\title{
Investigation of Precipitates in Dissimilar Weldments of Alloy 690 and SUS 304L with Nb addition in the electrodes
}

\author{
H.T. Lee *, S.L. Jeng * and W. P. Rehbach ${ }^{* *}$ \\ * National Cheng Kung University (NCKU), Department of Mechanical Engineering, \\ No.1, Ta-Hsueh Road, Tainan City, Taiwan ROC. \\ ** Aachen University (RWTH), Central Facility for Electron Microscopy (GFE), \\ 52056 Aachen, Germany
}

In this study dissimilar weldments of Nickel-based Alloy 690 and SUS 304L are presented, in which various contents of niobium $(\mathrm{Nb})(0.1 \%, 1.03 \%, 2.49 \%, 3.35 \%$ by weight $)$ were added in the flux of the electrodes. With identical parameters and procedures, weldments were butt welded using three layers by the Shielding Metal Arc Welding (SMAW) process, with each layer being deposited in a single pass.

Alloy 690 (30\% Cr-60\% Ni-9\% Fe), with its high chromium and low carbon contents, has a superior corrosion resistance in high temperature corrosive environments and has become one of the important materials in energy industries and chemical industries [1]. The principal motive for this choice is that $\mathrm{Nb}$ has a higher affinity for $\mathrm{C}$ than $\mathrm{Cr}$ and so theoretically $\mathrm{C}$ will react faster with $\mathrm{Nb}$ than it will with $\mathrm{Cr}$. Moreover, from Lee and Kuo's study [2], it was indicated that $\mathrm{Nb}$ also enhances the strength of Alloy 690 weldments at room temperature.

The investigations were performed with a FEG-SEM of type LEO Gemini and an EDX system of type Oxford Isis 300. To avoid subrate influence with the analysis of small precipitates, in addition to standard analysis at 15 to $20 \mathrm{kV}$ low voltage SEM at 3 to $8 \mathrm{kV}$ was performed. This resulted in optimum analysis conditions for light-element analysis [1].

The results indicate that the microstructure of the fusion zone is mainly dendritic. With $\mathrm{Nb}$ addition, the dendritic structure changes from cellular to columnar dendrite and equiaxed dendrite.. Meanwhile, the interdendritic phase increases as well.

The cap weldment with low $\mathrm{Nb}$ addition $(0.1 \mathrm{wt}-\%)$ contains eutectic phases which are rich in carbon or oxygen.

The root weldment obviously contains sphere-like and plate-like Cr-carbides, containing oxygen in different amounts.

In the weldment with high $\mathrm{Nb}$ addition (3.35 wt-\%), Nb-rich phases composed of $\mathrm{Nb}$-carbides and Laves phases appear.

In the cap weldment, the $\mathrm{Nb}$-rich phase is large and seems to be Laves phase with $30-40 \mathrm{wt}-\% \mathrm{Nb}$. Due to the effect of dilution, the root weldment has smaller Nb-rich phases than the cap layer. The Nb-rich phases contain up to $70 \mathrm{wt}-\% \mathrm{Nb}$ and are assumed to be Nb-carbides (Fig. $1 \mathrm{~d}$ ). Only a few Laves phases were found in this region (Fig. 1 e).

References

[1] C.M. Brown et al., Corrosion 55 (1999), No.2, 173-186.

[2] H.T. Lee and T.Y. Kuo, Sci. and Tech. of Weld. and Join. 4 (1999), No.4, 246-256.

[3] I. Barkshire et. al., Mikrochim. Acta 132 (2000), 113-128. 


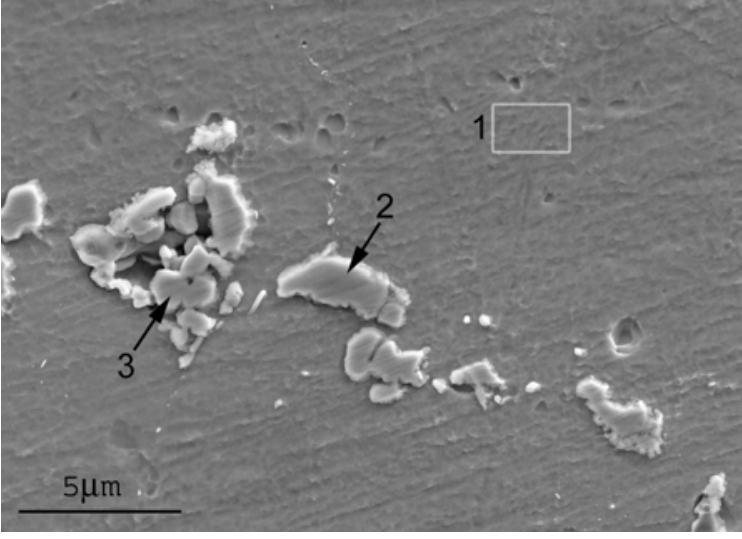

Fig. 1: SE-micrograph and EDX-spectra of matrix (1) and precipitates (2), (3).
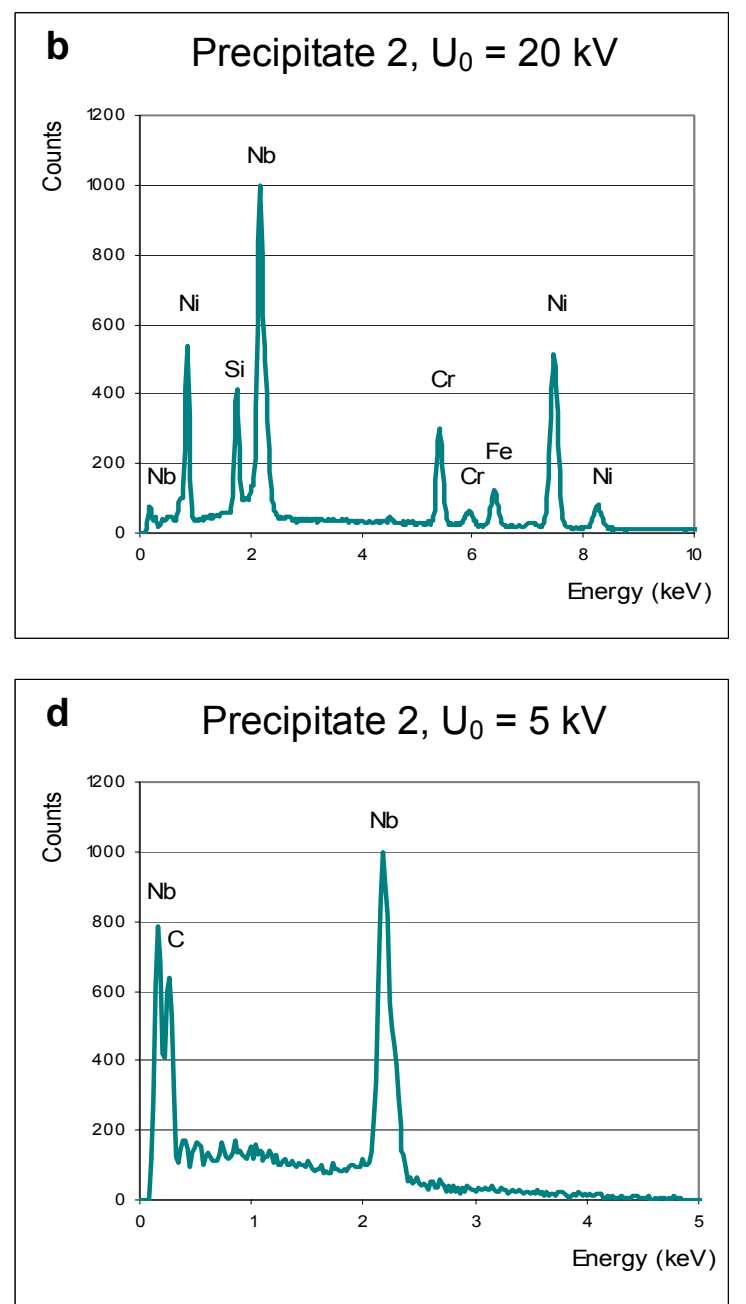
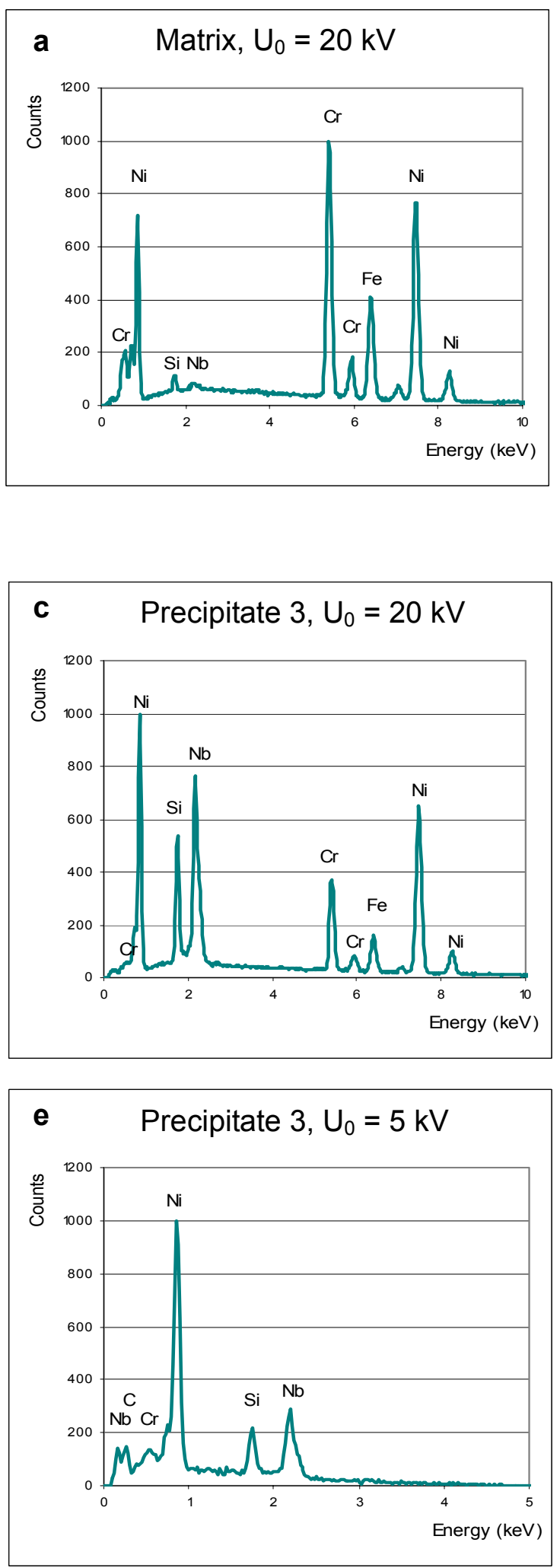